\title{
ASCO 2007: What Remains Important for Breast Cancer Systemic Therapy in the Routine Setting?
}

\author{
Nadia Harbeck ${ }^{\mathrm{a}} \quad$ Brigitte Rack $^{\mathrm{b}}$ Wolfgang Janni ${ }^{\mathrm{b}}$ \\ a Frauenklinik der Technischen Universität München, \\ b. Universitätsfrauenklinik Maistrasse der LMU München, Germany
}

Key Words

ASCO - Breast cancer · Lapatinib - Taxanes · Trastuzumab

\section{Summary}

The 43rd ASCO Annual Meeting took place from June 1-5, 2007 at McCormick Place in Chicago, IL, USA. This year's meeting had the special theme of 'Translating Research into Practice', particularly featuring 445 abstracts on translational research in addition to approximately 2,000 abstracts presented on subjects like surgery, radiation therapy, chemotherapy, endocrine therapy, and targeted therapies. This short summary will focus on the two important breast cancer oral presentation sessions only, and will try to comment on the presented data with regard to their immediate impact on clinical practice. Many more research results regarding breast cancer were presented (all presentations will be available to the public from September 1, 2007 at www.asco.org). In general, breast cancer data presented at this year's ASCO Annual Meeting confirmed current standards, and introduced promising new substances which may soon enter clinical practice. The 44th ASCO Annual Meeting will again be held in Chicago from May 30 to June 3, 2008. Those who do not want to wait another year may visit ASCO's first special Breast Cancer Symposium taking place September 7-8, 2007 in San Francisco, CA, USA. Whether this meeting will start a new tradition of a specialized ASCO breast cancer symposium, and how this development will eventually will impact on the regular San Antonio Breast Cancer Symposium in December, only time will tell.

\author{
Schlüsselwörter \\ ASCO - Brustkrebs · Lapatinib - Taxane - Trastuzumab
}

\section{Zusammenfassung}

Die 43. jährliche ASCO-Tagung fand dieses Jahr vom 1. bis 5. Juni im McCormick Place, Chicago, IL, USA statt. In diesem Jahr stand die Tagung unter dem Motto: "Translating Research into Practice» und präsentierte $445 \mathrm{Ab}$ strakts über translationale Forschung zusätzlich zu den über 2000 Abstrakts über Chirurgie, Strahlentherapie, Chemotherapie, endokrine und zielgerichtete Therapie (alle Beiträge sind ab dem 1. September 2007 öffentlich zugänglich unter www.asco.org). Dieser kurze Übersichtsartikel legt seinen Schwerpunkt auf die beiden wichtigen Vortragssitzungen über Brustkrebs und versucht die präsentierten Daten mit einem kurzen Fazit zu ihrer klinischen Relevanz zu kommentieren. Insgesamt bestätigten die in diesem Jahr gezeigten Daten zum Thema Brustkrebs die derzeitigen Therapiestandards und zeigten neue Therapieoptionen mit zielgerichteten Substanzen auf. Im nächsten Jahr wird die ASCO-Tagung wieder in Chicago abgehalten (30. Mai bis 3. Juni 2008). Diejenigen, denen die Wartezeit bis dahin zu lang ist, können sich in diesem Jahr erstmalig auf einem speziellen ASCO Brustkrebs-Symposium (7. bis 8.September 2007) in San Francisco, CA, USA, informieren. Ob dieser Kongress eine neue Tradition spezialisierter ASCO Brustkrebs-Jahrestagungen starten wird und wie sich dies dann auf das alljährliche San Antonio Breast Cancer Symposium im Dezember auswirken wird, bleibt abzuwarten.

\begin{tabular}{ll}
\hline KARGER & ( 2007 S. Karger GmbH, Freiburg \\
Fax +49 7614520714 & Accessible online at: \\
$\begin{array}{l}\text { E-mail Information@Karger.de } \\
\text { www.karger.com }\end{array}$ & www.karger.com/brc
\end{tabular}




\section{Introduction}

The 43rd ASCO Annual Meeting took place from June 1-5, 2007 at McCormick Place in Chicago, IL, USA. This year's meeting had the special theme of 'Translating Research into Practice', particularly featuring 445 abstracts on translational research in addition to approximately 2,000 abstracts presented on subjects like surgery, radiation therapy, chemotherapy, endocrine therapy, and targeted therapies. This short summary will focus on the important breast cancer oral presentation sessions only, and will try to comment on the presented data with regard to their immediate impact on clinical practice.

\section{Adjuvant Therapy}

The 2007 adjuvant breast cancer oral presentation session was chaired by Jenny Chang (Baylor College, Houston, TX, USA) and Mark Pegram (UCLA, Los Angeles, CA, USA). There were no talks on endocrine therapy trials in this session.

Edith Perez presented an update of the joint analysis of the NCCTG9831 and NSABP-B31 adjuvant trastuzumab trials (abstract 512) which included 3,968 patients, 619 events, and 258 deaths. After a longer median follow-up of now 2.9 years, the previously observed clinical benefit of 1 year of adjuvant trastuzumab remains stable in the intent-to-treat analysis despite a total crossover of $20.9 \%$ of patients $(n=413)$ from the control arm to trastuzumab therapy: The estimated relapsefree survival after 4 years was 85.9 vs. $73.1 \%$, with an adjusted hazard ratio (HR) of 0.48 (95\% confidence interval (CI) $0.41-0.57), \mathrm{p}<0.00001$. No survival benefit could be seen in the very small subgroup of node-negative patients (approximately $7 \%$ ), yet all other clinically relevant subgroups do benefit from trastuzumab therapy. The estimated overall survival (OS) after 4 years was 92.6 vs. $89.4 \%$, with a HR of $0.65(95 \% \mathrm{CI}$ $0.51-0.84), p=0.0007$. The highest event rates (including recurrent disease, contralateral breast cancer, second primary, death) were seen between years 2-3 in the trastuzumab as well as in the control arm with a sharp decline after year 3 in both arms. In NCCTG9831, total cardiac complications were significantly different between the 2 study arms (trastuzumab yes/no) with 2.5 vs. $0.2 \%$ at 3 years. In a late breaking abstract (LBA 513), Priva Rastogi presented an update of the cardiac safety data of NSABP B-31 showing that the overall congestive heart failure $(\mathrm{CHF})$ rate has remained rather stable over time with now $3.8 \%$ (vs. $0.9 \%$ ) after 5 years, compared to $4.1 \%$ (vs. $0.8 \%$ ) after 3 years (data shown at ASCO 2005). There are now a total of 35 patients with $\mathrm{CHF}$ (no deaths) vs. 6 patients in the control arm (1 death). In multivariate analysis, the major risk factors for developing cardiac dysfunction were older age, low baseline left ventricular ejection fraction (LVEF), and hypertensive medication. In conclusion, the survival advantage gained by 1 year of adjuvant trastuzumab remains strong and stable after longer follow-up. Optimal therapy duration and se- quence for clinical routine remain open questions. With regard to cardiotoxicity, starting trastuzumab therapy parallel to taxane-containing adjuvant chemotherapy seems to be associated with a CHF rate of approximately $4 \%$. Particularly at risk are women aged 50 or older, those on antihypertensive medication, those with a LVEF $<55$ at baseline or after doxorubicin/ cyclophosphamide (AC) chemotherapy.

Three talks in the main session, addressed the adjuvant use of taxanes: A pooled analysis of 2 adjuvant docetaxel trials, BCIRG001 and PACS 01 ( $\mathrm{n}=3,490)$, showed that the superiority regarding disease-free survival (DFS) and OS of docetaxel-containing adjuvant chemotherapy compared to a standard anthracycline regimen is independent of the estrogen receptor (ER) status as well as the degree of ER expression (Andre et al., abstract 537). The E1199 trial $(\mathrm{n}=5,052)$ which had already been presented at the San Antonio Breast Cancer Symposium (SABCS) 2005 compared the two taxanes, paclitaxel and docetaxel, given weekly or every 3 weeks (after 4 cycles of AC) without being able to show a significant efficacy difference in relation to type of taxane or schedule (Sparano et al., abstract 516). The best 5-year DFS rates were achieved by weekly paclitaxel $(81.5 \%)$ and 3-weekly docetaxel $(81.2 \%)$. Accordingly, compared to 3-weekly paclitaxel, the largest relapse risk reductions (approximately 25\%) were reached by weekly paclitaxel or 3-weekly docetaxel. The 5-year update (Loesch et al., abstract 517) of the phase III trial comparing adriamycin/paclitaxel followed by weekly paclitaxel $(\mathrm{AP} \rightarrow \mathrm{P})$ vs. the Henderson regimen $(\mathrm{AC} \rightarrow \mathrm{P})$ did not confirm the DFS advantage observed in the 3-year follow-up which was presented at SABCS 2004. In this second analysis, no benefit was found regarding 5-year DFS ( $\mathrm{p}=0.38)$, and only a borderline OS advantage for $\mathrm{AP} \rightarrow \mathrm{P}$ with 90 vs. $87 \%$ at 5 years (HR 0.76; $\mathrm{p}=0.04)$. Triple negative patients did seem to derive a particular benefit from $\mathrm{AP} \rightarrow \mathrm{P}$ as unplanned subgroup analyses showed. In conclusion, adjuvant taxane-containing chemotherapy remains a standard for node-positive patients regardless of the hormone receptor status. In a sequence of $\mathrm{AC}$ followed by a taxane, both weekly paclitaxel and 3-weekly docetaxel seem to be more effective than 3-weekly paclitaxel or weekly docetaxel.

\section{Therapy of Metastatic Breast Cancer}

The 2007 metastatic breast cancer oral presentation session was chaired by Antonio Wolff (Sidney Kimmel Comprehensive Cancer Center at Johns Hopkins, Baltimore, MD, USA) and Nadia Harbeck (Technical University of Munich, Germany). A number of talks addressed new combinations, in particular those of a chemotherapy regimen with targeted drugs. Mark Pegram (LBA 1008) showed the first OS analysis of BCIRG 007 (i.e. docetaxel100/trastuzumab (TH) vs. docetaxel75/carboplatin AUC5/trastuzumab (TCH)) for which the DFS had already been presented at ASCO 2006. In first line 
therapy for metastatic breast cancer, there is no survival advantage of TCH vs. TH after a median follow-up of 39 months ( $\mathrm{n}=263$ ): The median OS TH vs. TCH was 36.40 vs. 36.57 months $(p=0.65)$. Neutropenic infections occurred at a rate of $16.8 \%(\mathrm{TH})$ vs. $9.2 \%(\mathrm{TCH})(\mathrm{p}=0.097)$ with no significant difference in the febrile neutropenia rate and 2 septic deaths (both with $\mathrm{TCH}$ ). The rate of thrombocytopenia was $2.3 \%$ $(\mathrm{TH})$ vs. $15.3 \%(\mathrm{TCH})(\mathrm{p}<0.01)$. In conclusion, in contrast to the adjuvant setting, the $\mathrm{TCH}$ regimen does not offer any substantial advantage (vs. TH) in the metastatic setting, and should thus not be considered a standard regimen in this therapy indication.

Angelo di Leo (abstract 1011) presented the phase III trial of first line therapy with paclitaxel $(\mathrm{P})$ vs. paclitaxel/lapatinib (PL) in HER2-negative disease $(\mathrm{n}=580)$. In blinded central re-evaluation, $19 \%$ of patients in the PL and $15 \%$ in the $\mathrm{P}$ arm had HER2-positive disease. Adverse events (e.g. rash, diarrhea, and mucositis) were higher in the PL arm. Among serious adverse events (SAE), only diarrhea was significantly higher ( 8 vs. $<0.1 \%$; $<<0.0001$ ) in the PL arm. SAE-related deaths were more common in the combination arm (2.7 vs. $0.6 \%)$. As expected, the management of side effects, in particular diarrhea, improved over time. In the total patient group, there was no survival (time to progression (TTP), OS) advantage for the addition of lapatinib to paclitaxel chemotherapy. Yet, in HER2-positive disease, there was an advantage for PL regarding response rate ( 60 vs. $36 \% ; p=0.027$ ), duration of response (median 7.4 vs. 5.5 months), and TTP (median 8.1 vs. 5.8 months; $\mathrm{p}=0.011$ ). OS did not differ significantly in HER2-positive disease. In conclusion, clinical effectiveness of the multikinase inhibitor lapatinib seems to be limited to HER2-positive disease even though its mechanism of action does suggest additional HER2-independent efficacy. This underlines the importance of appropriate patient selection and target determination for targeted therapy trials.

The EGF 105084 trial (Lin et al., abstract 1012) evaluated lapatinib monotherapy (750 mg twice daily) in patients with HER2-positive brain metastasis after trastuzumab and cranial radiotherapy $(n=241)$. In $19 \%$ of patients, a maximum tumor volumetric reduction of the central nervous lesions of at least $20 \%$, and in $7 \%$ of patients of at least $50 \%$, was observed. Median progression-free survival (PFS) under lapatinib monotherapy was 15.1 weeks with a 6-month PFS rate of $22 \%$. An extension period of this study with lapatinib/capecitabine is still being evaluated, but early response data suggest that the combination may be more effective ( $20 \%$ achieving $\geq 50 \%$ volumetric reduction and $40 \% \geq 20 \%$ ). In conclusion, lapatinib does have activity as a monotherapy in central nervous metastasis which is of course limited in the very advanced clinical situation evaluated in this trial. So far lapatinib monotherapy should therefore only be used in individual HER2 breast cancer cases with brain metastasis.

E. Alba (abstract 1007) presented the GEICAM 2001-01 phase III study looking at the benefit of a maintenance therapy with pegylated liposomal doxorubicin (PLD $40 \mathrm{mg} / \mathrm{m}^{2} \mathrm{q} 28$ ) after first line chemotherapy with an anthracycline-taxane sequence. Of the 288 patients initially registered, 155 with complete remission (CR), partial remission (PR), or stable disease (SD) were able to be randomized after induction chemotherapy. $50 \%$ completed all planned 6 cycles of PLD maintenance therapy. PLD maintenance significantly improved TTP after randomization (median 8.4 vs. 5.1 months; $\mathrm{p}=0.0006$ ), and after the initial induction treatment (median 13.2 vs. 10.2 months; $p=0.0005$ ) with manageable toxicity. In conclusion, maintenance therapy with 6 cycles of PLD is feasible after an anthracycline-taxane induction chemotherapy. It prolongs TTP by approximately 3 months with progressions being avoided while on maintenance chemotherapy. Yet, OS data are still lacking thus making maintenance therapy an option only in individual patients for whom progression needs to be avoided and an endocrine maintenance therapy is not available.

The XCALIBr trial looked at safety and efficacy of first line capecitabine $\left(1,000 \mathrm{mg} / \mathrm{m}^{2}\right.$ twice daily) and bevacizumab (Sledge et al., abstract 1013) with a median follow-up of 12.9 months being reported at ASCO this year. In 106 HER2-negative tumors, the overall response rate (ORR: CR + PR) was $38 \%$ with the combination being well tolerated. Median TTP of 5.7 months was significantly longer for the combination than estimated for capecitabine monotherapy (4 months). Patients with ER-positive disease derived particular benefit with a median TTP of 8.9 vs. 4.0 months for ER-negative disease. In conclusion, capecitabine/bevacizumab is an active combination in first line therapy which adds another first line option to the registered paclitaxel/bevacizumab combination. Whether the particular benefit in ER-positive disease is bevacizumabrelated or due to an endocrine impact on the capecitabine metabolism, cannot be decided at this point. In addition, data from the pre-defined second line chemotherapy + bevacizumab study part will help to clarify therapy options after progression on bevacizumab and first line chemotherapy.

\section{Conclusion}

Obviously, many more research results regarding breast cancer were presented (all presentations will be available to the public from September 1, 2007 at www.asco.org). In general, breast cancer data presented at this year's ASCO Annual Meeting confirmed current standards and introduced promising new substances which may soon enter clinical practice. The 44th ASCO Annual Meeting will again be held in Chicago from May 30 to June 3, 2008. Those who do not want to wait another year may visit ASCO's first special Breast Cancer Symposium taking place September 7-8, 2007 in San Francisco, CA, USA. Whether this meeting will start a new tradition of a specialized ASCO breast cancer symposium, and how this development will eventually will impact on the regular SABCS in December, only time will tell. 